\title{
The junior referee conundrum: how do you gain experience with the peer review process?
}

\author{
Michael R. Donaldson \\ Michael R. Donaldson (Michael.r.donaldson@gmail.com), Pacific Salmon Ecology and Conservation Laboratory, \\ Centre for Applied Conservation Research and Department of Forest Sciences, University of British Columbia, \\ Vancouver, British Columbia, Canada
}

Peer review is a unique process that provides a means through which we, as scientists, can ensure we produce high quality research that furthers scientific knowledge. With the tragedy of the reviewer commons (Hochberg et al. 2009), it has been proposed that junior referees should be increasingly engaged in the peer review process to help mitigate the problem of dwindling reviewer availability (Donaldson et al. 2010). However, as Donaldson et al. (2010) found, some editors of major ecology journals are skeptical of relying on junior referees due to their lack of experience. Junior referees provide an interesting conundrum: one should have experience before they conduct a peer review, but how can one gain experience as a reviewer without actually reviewing a manuscript? This problem is analogous in many ways to applying for a job that requires a potential employee to have experience in the given field, but the applicant has no means of gaining experience without a job. As with the job-seeking analogy, education combined with practical experience (e.g., volunteering) is a typical solution. In effect, Lepczyk and Donnelly (2011) are suggesting such an approach in their guide to reviewing manuscripts. Lepczyk and Donnelly help to educate junior referees by providing an overview of the rich history of peer review in the development of modern science, establishing the role of junior referees in the process, encouraging critical thinking, and suggesting a golden set of standards to ensure that referees remain constructive in their critical reviews. Guiding junior referees down the right path is essential to encouraging quality reviews, but we must also provide junior referees with opportunities to conduct reviews.
As a junior referee, I can share my insight into how I have gained experience in the peer review process. Like most graduate students, I began my graduate studies with little knowledge of, and no experience with, the peer review process. However, since beginning my M.Sc. studies in 2006, I have gained a great deal of experience through publishing my own research and serving as a referee on over 20 manuscripts. Only recently would I say that I finally feel 'comfortable' conducting reviews. The idea of evaluating someone else's hard work, and determining whether or not their research is suitable for publication is certainly an intimidating prospect, particularly when the authors can be leaders in your field of research! My personal level of comfort has only increased because-through experience-I have become more confident in my ability to think critically. While I am still learning and I know I have a long way to go (likely an entire career's worth of conducting reviews), I have gained immensely in my ability to think critically and provide constructive reviews, simply through experience. I am grateful for the opportunities that I have had to conduct reviews as they have given me insight into the peer review process and have helped to improve my own writing.

So how does one gain experience as a referee? While Lepczyk and Donnelly (2011) provide an excellent resource for how to conduct a review, junior referees also need to consider how to gain reviewing opportunities so that they can use the guide in practice. Gaining experience in peer review as early as possible in graduate school (or even senior undergraduate courses) is imperative, as it not only helps mitigate the tragedy of the reviewer commons, but also provides 
immeasurable experience to the junior referees. Thinking critically about previously published journal articles you read for thesis research is a great start (e.g., were the methods designed to effectively address the stated objectives? Were proper statistical tests used? Are the conclusions warranted?). I have been fortunate to have graduate supervisors who have actively encourageed their students to get interested in peer review by getting them involved in the articles they are reviewing. For example, lab meetings can be scheduled and a group review conducted. Senior graduate students with experience publishing and conducting reviews are likewise important resources. Graduate departments should consider hosting peer review workshops where experienced faculty members should share their experiences and advice. In some cases, entire graduate courses are designed around the peer review process, providing exceptionally detailed insight into this important part of science.

Another method to gain experience with the peer review process is to submit your own research for review. As many researchers can attest, the range of reviews you will receive is remarkable. For example, I have experienced excellent positive reviews (i.e., the referees were supportive of the research and provided ideas on how to improve the work further), excellent negative reviews (i.e., the referees did not feel the manuscript should be accepted, but provided constructive feedback on how to improve the work for a subsequent re-submission), poor positive reviews (i.e., the referees provided little to no feedback, but recommended the paper for publication), and most frustratingly, poor negative reviews (i.e., the referees were highly critical of the paper, but provided little constructive feedback on how to improve it), and every combination in between. Receiving a poor quality review of your own work can be frustrating, but it can be an important reminder that, when you serve as a referee, you should strive to provide quality feedback to authors to help them improve their paper. The golden rules introduced by McPeek et al. (2009) and suggested by Lepczyk and Donnelly (2011) provide great advice on how to ensure that your reviews are constructive, re-gardless of whether or not they are positive or negative. Afterall, we want to avoid turning junior referees into 'pitbulls' (Walbot 2009).

In order to be considered as a reviewer, students need to 'get on the grid' by making editors aware of their expertise and availability to conduct reviews. This can be done through students publishing their own work (e.g., author and co-author contact details are kept in databases as potential reviewers by most publishers). Supervisors and colleagues can suggest their students' names to editors when appropriate. If a potential reviewer is unable to conduct a review due to time constraints, editors could encourage this person to suggest the name of an appropriate student or post-doctoral researcher from their research group to conduct the review in their stead. Professional societies often keep lists of potential reviewers (including student reviewers specifically) so that graduate students can contact the societies in order to list their own names in these databases.

As academics, we have the shared responsibility of contributing to the peer review process. Engaging junior referees early in their career is highly valuable, but we must provide guidelines and opportunities to do so. Putting the principles of the guide into practice by making the most of reviewing opportunities is the only way to develop and become proficient as a referee. Increasing the involvement of junior referees provides an immediate surge in the diminishing referee pool and helps to ensure the sustainability of the peer review process over the long term by training the referees of tomorrow, today.

\section{References}

Donaldson, M.R., Hasler, C.T., Hanson, K.C., Clark, T.D., Hinch, S.G. and S.J. Cooke. 2010. Injecting youth into peer review to ensure its sustainability: a case study of ecology journals. Ideas in Ecology and Evolution 3: 1-7. CrossRef

Hochberg, M.E., Chase, J.M., Gotelli, N.J., Hastings, A. and R. Naeem. 2009. The tragedy of the reviewer commons. Ecology Letters 12: 2-4. CrossRef

Lepczyk, C.A. and R.E. Donnelly. 2011. A beginner's guide to reviewing manuscripts in ecology and conservation. Ideas in Ecology and Evolution 4: 2531. CrossRef

McPeek, M.A., DeAngelis, D.L., Shaw, R.G., Moore, A.J., Rausher, M.D., Strong, D.R., Ellison, A.M., Barrett, L., Rieseberg, L., Breed, M., Sullivan, J., Osenberg, C.W., Holyoak, M. and M.A. Elgar. 2009. The golden rule of reviewing. The American Naturalist 173: E155-E158. CrossRef

Walbot, V. 2009. Are we training pitbulls to review our manuscripts? Journal of Biology 8: 24. CrossRef 